\title{
UNDERREAMED GROUND ANCHORS
}

\section{Ancrage dans le sol avec élargissement}

\author{
by \\ Richard H. BASSETT \\ University of London King's College - Civil engineering Strand-London WC 2R 2LS - Great Britain
}

\begin{tabular}{|c|c|}
\hline SOMMAIRE & SUMMARY \\
\hline $\begin{array}{l}\text { Les ancrages dans le sol acquièrent une impor- } \\
\text { tance grandissante pour les appuis de murs de } \\
\text { soutènement, aussi bien en terrains cohérents qu'en } \\
\text { terrains non-cohérents. Pour les sols cohérents, le } \\
\text { rendement de la portance d'un ancrage augmente } \\
\text { avec la construction d'élargissements sur le fût. } \\
\text { Les formules empiriques qui permettent de calculer } \\
\text { cette charge utile proviennent de la théorie des } \\
\text { pieux. L'étude examine, au moyen d'expériences } \\
\text { en laboratoire, les caractéristiques suivantes des } \\
\text { ancrages à élargissements de diamètre: influence } \\
\text { des distances entre les élargissements, influence } \\
\text { du nombre de ceux-ci et relation entre rigidité du } \\
\text { sol et rigidité du câble de l'ancrage. L'observation } \\
\text { des mécanismes de rupture montre que les élé- } \\
\text { ments individuels de la formule empirique sont } \\
\text { justifiés, ce quí permet de suggérer des valeurs } \\
\text { pour les dimensionner. }\end{array}$ & $\begin{array}{l}\text { Ground anchors are becoming increasingly impor- } \\
\text { tant for supporting retaining walls in both cohesive } \\
\text { and non-cohesive soils. In cohesive soils the } \\
\text { efficiency of an anchor's carrying capacity is } \\
\text { improved by forming underreams on the shaft. } \\
\text { Empirical formulae for calculating their load capacity } \\
\text { have been developed from piling philosophy. The } \\
\text { paper examines by controlled laboratory experi- } \\
\text { ments the following features of underreamed } \\
\text { anchors: The influence of the spacing of under- } \\
\text { reams, the influence of the number of underreams } \\
\text { and the relationship between the soil stiffness and } \\
\text { the anchor tendon stiffness. The observed failure } \\
\text { mechanisms show that the format of the empirical } \\
\text { formula is justified and values for design constants } \\
\text { are suggested. }\end{array}$ \\
\hline
\end{tabular}

\section{INTRODUCTION}

The rapid increase in the economic importance of holding back permanent retaining wall structures by the use of anchor ties was indicated by Ostermayer (1974). The exponential increase suggested has continued unabated and in the author's personal experience appears to be coupled with a continuous demand for increased load capacity. Practical anchoring techniques fall into two distinct catagories,

a) Pressure grouted or regrouted shafts, relying on the adhesion bond between the face of a grout mortar body and the soil (most commonly used in cohesionless soils and rock), or

b) Open drilled shafts in which the anchorage zone is deliberately expanded in diameter to form a series of bells or underreams (most commonly used in self supporting soils from fine cohesive clays to moderately hard rocks).

Although a considerable body of literature has now been collected, Littlejohn (1975), these predominantly concern either practical examples, wall-anchor interaction studies or fundamental laboratory tests of anchor plate systems in dry sand. Little fundamental study, with the exception of Ostermayer (1974), appears to be available to justify the empirical design formula (Littlejohn 1970a 1970b) recommended for the real construction methods.

The author has been working on both groups. But this paper will present only data obtained from a controlled laboratory examination of the behaviour of multi-underreamed anchors in a very low permeability, saturated, uniform, cohesive material.

\section{THE UNDERREAMED ANCHOR PRINCIPLE}

Straight shaft, pressure grouted anchors have been used in cohesive materials but boring the hole invariably results in the remoulding of a thin layer of soil adjacent to the final anchor member. The considerable, consequent reduction in strength can rarely be compensated for even by pressure grouting. Underreams cut out into undisturbed soil at intervals along the shaft induce a cylindrical shear failure although intact soil (fig. 1). Various patented cutting techniques are employed in the U.K. the blade cutter of Universal Anchorage Limited and the expanding brush of the Cementation Company are typical instances. 
Dr. Littlejohn (1970a 1970b) presented an empirical formula (1) for estimating the ultimate capacity of this type of anchor based quite logically on piling philosophy

$$
\begin{array}{r}
\mathrm{W}_{\mathrm{ult}}=\mathrm{N}_{c} \cdot\left(\mathrm{D}^{2}-\mathrm{d}_{s}{ }^{2}\right) \frac{\pi}{4} \cdot c_{u}+\pi \mathrm{D} \cdot l_{u} \cdot c_{u}+ \\
f_{s} \cdot \pi d_{s} \cdot l_{s} \cdot c_{u}
\end{array}
$$

end bearing + capacity of underream length + capacity of shaft length.

The author, Bassett (1970) in his discussion to this paper and in Bassett (1971) had derived a similar formula (2) based on the full scale testing of some 500 production clay anchors but the author included a reduction coefficient $f_{\mathrm{u}}$ to be applied to the capacity of the underream length and questioned Littlejohn's $\mathrm{N}_{c}$ value (see Littlejohn's reply (1970) c).

$$
\begin{gathered}
\mathrm{W}_{\text {ult }}=\mathrm{N}_{c} \cdot\left(\mathrm{D}^{2}-d_{s}{ }^{2}\right) \frac{\mathrm{I1}}{4} \cdot c_{u}+f_{u} \cdot \Pi \cdot \mathrm{D} \cdot l_{u} \cdot c_{u}+ \\
f_{s} \cdot \Pi \cdot d_{s} \cdot l_{s} \cdot c_{u}
\end{gathered}
$$

Under the author's direction Potts (1973) set out to investigate both the fundamental components of this empirical equation and possible alternative analytical approaches. His work on the following is presented here:-

(i) The examination of the behaviour of a single underream in order to measure the Terzaghi bearing capacity factor $\mathrm{N}_{c}$ and to assess the influence of the cavity which forms below an underream on rapid loading.

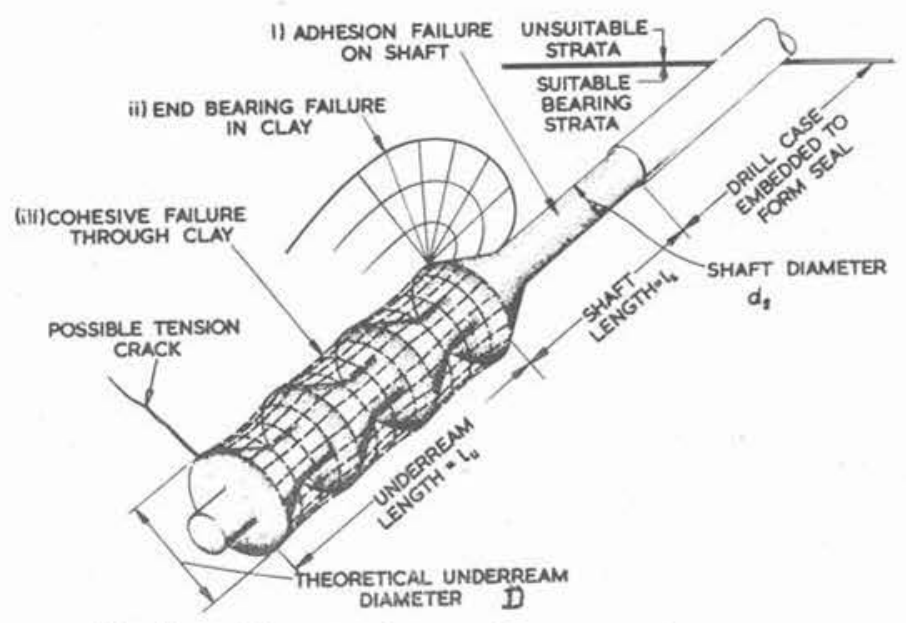

Fig. 1. - Diagram of an underream anchor.

(ii) The examination of the mechanism of failure to justify the format of the empirical equation (2).

(iii) The examination of the influence of varying the spacing of underream bells.

(iv) The effect on the load capacity of increasing the number of underreams and to relate this effect to the ratio between the stiffness of the anchor tendon system and the equivalent response stiffness of the soil deformation mechanism.

\section{EQUIPMENT AND TEST PROCEDURE}

All the tests described were performed on a saturated, remoulded, reconsolidated, London clay with the following specification ;

$\begin{array}{lr}\text { Water content } & 43 \% \\ \mathrm{LL} & 86 \% \\ \mathrm{PL} & 23 \% \\ \mathrm{PI} & 63 \% \\ \text { Liquidity Index } & 0.35 \\ \text { Undrained triaxial shear } \\ \text { strength } 40 \mathrm{KN} / \mathrm{m}^{2} \text {. }\end{array}$

This is in good agreement with Skempton and Northey (1953). The data indicated an undrained $E$ (at $1 / 2 \%$ strain) $=15 \times 10^{5} \mathrm{~N} / \mathrm{m}^{2}$.

The anchor was formed of $30 \mathrm{~mm}$ diameter, stiff, aluminium discs some of which incorporated a strain gauged load transducer. These discs represented the underream bells and were connected by various lengths of rod, hollow hypodermic tube, or stiff springs to represent the tendon system. The load carrying zone formed by the discs was deeply embedded (depth/ diameter $>15$ ) in the clay contained in a $380 \mathrm{~mm}$ dia. $\times 900 \mathrm{~mm}$ high cylindrical container (fig. 2). The lateral pressure in the soil was initially fixed and monitored by instrumented bolts.

All tests were performed at a constant pull out rate of $1.7 \times 10^{-2} \mathrm{~mm} / \mathrm{s}$. For saturated, remoulded London clay this is effectively rapid and undrained.

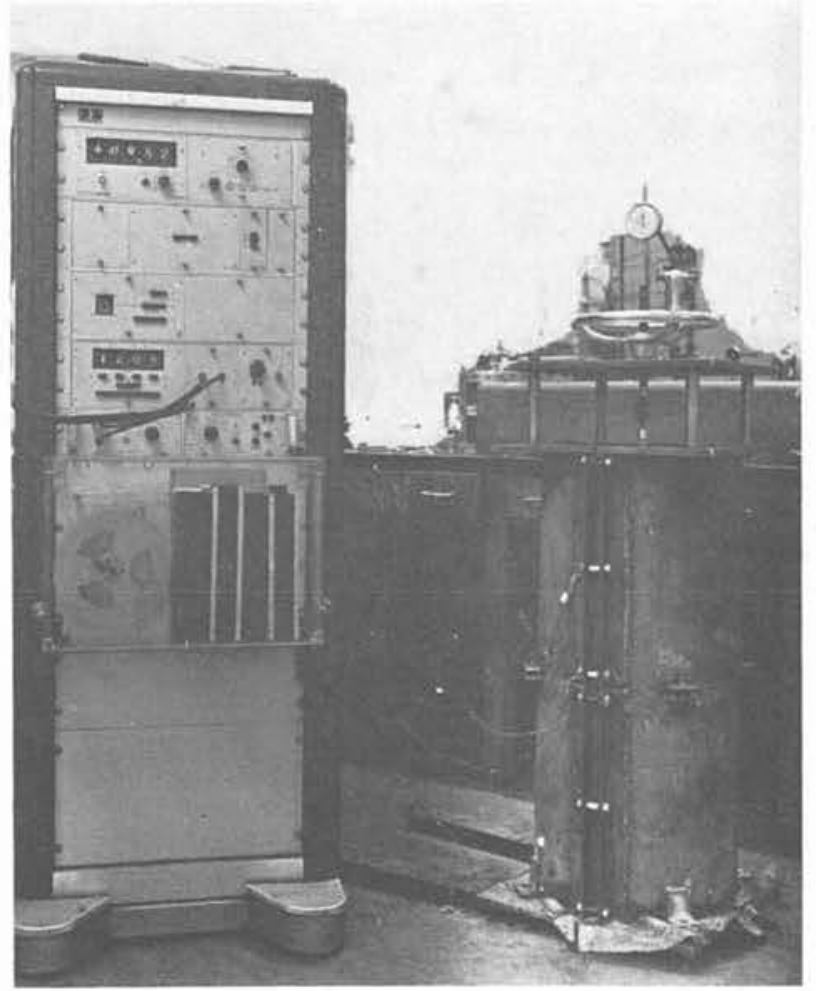

Fig. 2. - Photograph of the test equipment. 


\section{THE SINGLE UNDERREAM}

Two initial tests were performed on single discs the first with a hollow tube tendon venting the area below the disc to atmosphere, the second with a solid stem. The results are shown in figure 3 as curve $A$ and curve $B$ respectively.

The vented disc, A, reaches its initial failure in end bearing at approximately $1 \mathrm{~mm}$ displacement. Curve B shows a similar basic format the pressure difference between Curve A and B representing the suction on the underside of the disc is shown in figure 4. where $\mathrm{P}_{s}$ is the pressure required to expand the cavity and $\frac{c}{a}$ is the ratio of the cavity volume to the volume of the plastic zone.

$$
\text { i.e. } \frac{c}{a}=\left(\frac{\mathrm{E}}{(1-\mathrm{v}) 2 c_{u}}\right) \ldots \ldots \ldots .
$$

for $\mathrm{v}=0.5$ (undrained), $c_{u}=40 \mathrm{kN} / \mathrm{m}^{2}$,

$$
\mathrm{P}_{\mathrm{s}}=188 \mathrm{kN} / \mathrm{m}^{2}
$$

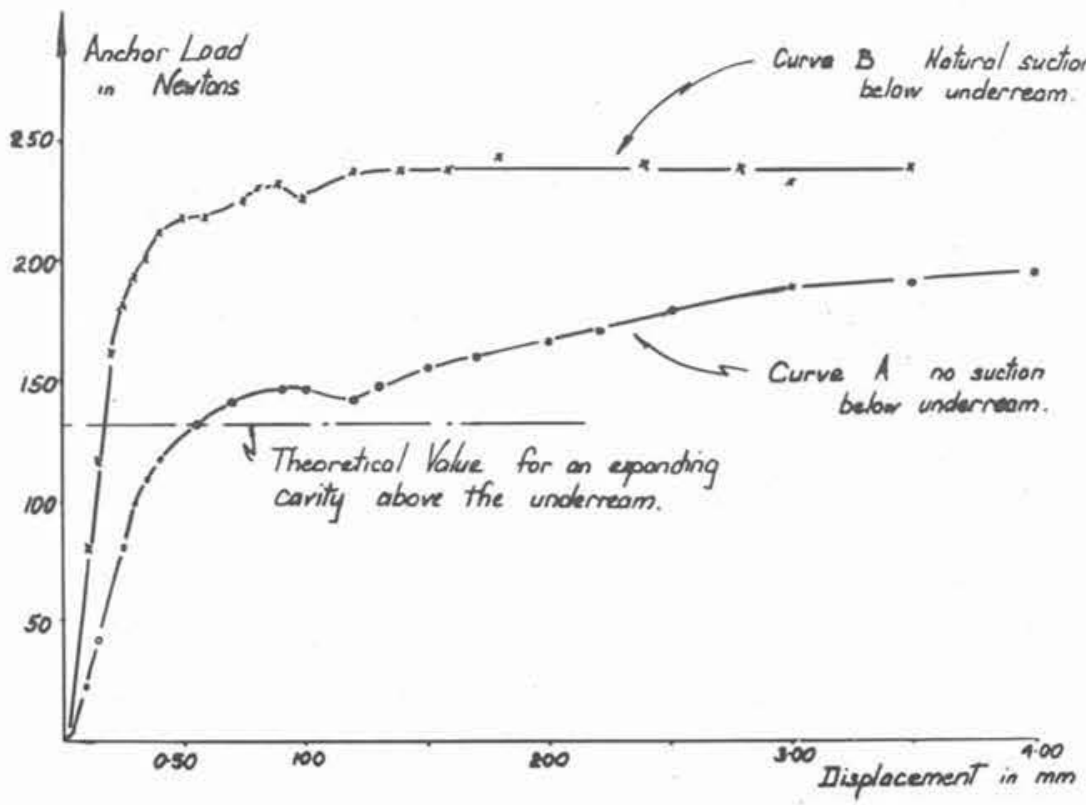

Fig. 3. - Load-displacement for a single underream.

Fig. 4. - Suction-displacement below a single underream.

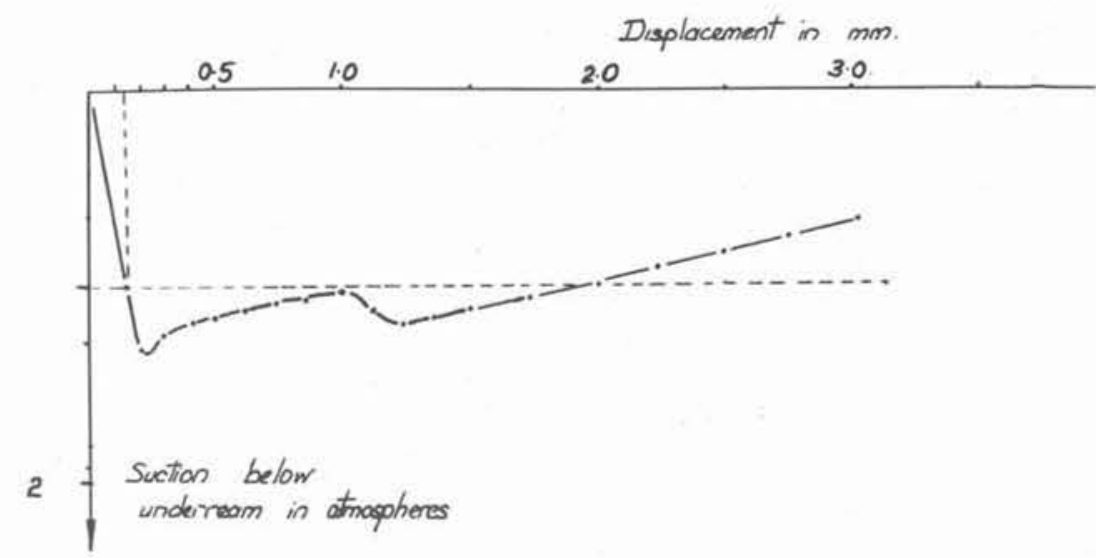

A suction pressure of one atmosphere is developed after only $0.15 \mathrm{~mm}$ displacement and reaches a peak in excess of this at $0.25 \mathrm{~mm}$ there after progressively decreasing. This is presumably due to evapouration at the free clay surface and a reduction in suction as water vapour fills the cavity. It is significant that a vacuum cannot be maintained even at this high rate of strain.

Potts (1973) adopted the expanding plastic cavity approach to provide a theoretical peak value for the ultimate load capacity of this single underream. He adopted from the work of Bishop, Hill and Mott (1945) the equation:

$$
\mathrm{P}_{s}=\frac{2}{3} c_{u}\left(1-3 \log _{e} \frac{c}{a}\right) \ldots \ldots \ldots .
$$

and over the area of the underream disc for a half cavity is equivalent to a force of: $-137 \mathrm{~N}$.

This value is drawn on figure 3 and is the theoretical estimate for the maximum value of curve $A$. The agreement is seen to be reasonably good. Swain (1976) has developed a similar theoretical argument but used a more extended approach to give the complete loaddisplacement relationship up to the initial failure.

The Conventional Terzaghi bearing capacity and the piling approach to this problem suggests a value of $\mathrm{N}_{c}=9$. (This value of $\mathrm{N}_{c}$ is used by Littlejohn 1970a $1970 \mathrm{~b})$. The experimental value for Curve $\mathrm{A}$ is $\mathrm{N}_{c}=5.4$ and for the total load including the suction component in Curve $\mathrm{B}$ is $\mathrm{N}_{c}=8.6$. 


\section{VERTIFICATION OF THE MECHANISM POSTULATE IN THE EMPIRICAL FORMULAE AND THE INFLUENCE OF UNDERREAM SPACING:}

As all the subsequent test series described in this paper allowed no venting below the bottom underream the higher value of $\mathrm{N}_{c}=8.4$ was adopted to include the suction component.

To check the failure mechanism an underream spacing of $1.5 \mathrm{D}$, consistent with practice, was adopted. This model was tested using a split sample, the clay surface being marked with a fine horizontal grid. During the test this grid was examined and typical photographs are shown in figure 5 .

The ruptures seemed to justify the empirical approach, assuming two major components (1) end bearing on the top underream and (11) a waisted plug like component for the main anchorage length. The pictures did however show a distinct indication of an end bearing passive cone above all the underreams before the plug failure was fully formed. This observation suggested that a transfer from the plug failure mechanism to a number of separate end bearing failures would almost certainly occur when the load capacity between two underreams reached the value of an end bearing failure, perhaps even earlier.

i.e. if the distance between two underreams $\mathrm{L}$ is thought of as a dimentionless ratio $\times$ diameter of underream (D)

$$
\text { i.e. } L=\left\{\frac{L}{D}\right\} \times D
$$

then for equal capacity of a plug failure and an end bearing failure

$$
\begin{aligned}
& f_{u} \cdot c_{u} \cdot \pi \cdot \mathrm{D} \cdot\left(\frac{\mathrm{L}}{\mathrm{D}}\right)_{\text {crit }} \cdot \mathrm{D}=\mathrm{N}_{c} \cdot c_{u} \cdot\left(\mathrm{D}^{2}-d_{s}{ }^{2}\right) \cdot \frac{\pi}{4} \\
& \text { or }\left(\frac{\mathrm{L}}{\mathrm{D}}\right)_{\text {crit }}=\frac{\mathrm{N}_{c}}{4 f_{u}} \cdot\left(\frac{\mathrm{D}^{2}-d_{s}{ }^{2}}{\mathrm{D}^{2}}\right)
\end{aligned}
$$

as $d_{s}$ is small compared to $\mathrm{D}$ then $\frac{\mathrm{L}}{\mathrm{D}_{\text {crit }}}=\frac{\mathrm{N}_{c}}{4 f_{u}}$

Section 5 of this paper will indicate the determination of $f_{u}=0.63$ and for this value and $\mathrm{N}_{c}=8.5$

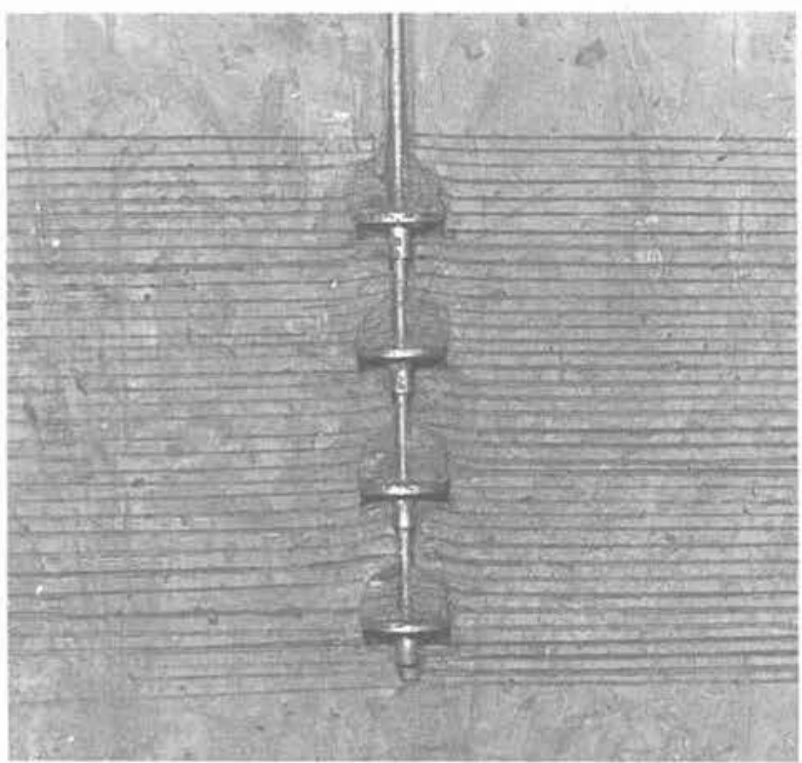

Fig. 5 a. - End bearing cones.

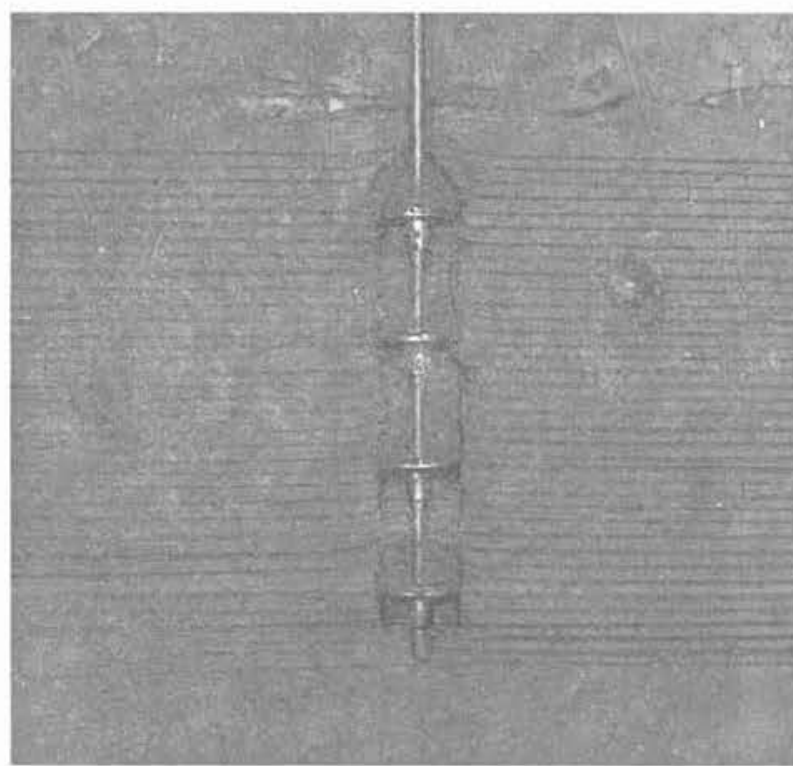

Fig. 5 b. - Plug failure.

the critical spacing ratio is equal to 3.4. Using the fully vented cavity value $\left(\frac{\mathrm{L}}{\mathrm{D}}\right)_{\text {crit }}$ reduces to 2.1 .

A series of unvented, rapid loading tests were carried out using 3 underream discs at spacings of $1.5 \mathrm{D}$ : 2D: $2.25 \mathrm{D}: 3 \mathrm{D}$ and $4 \mathrm{D}$. The results are shown in figure 6 .

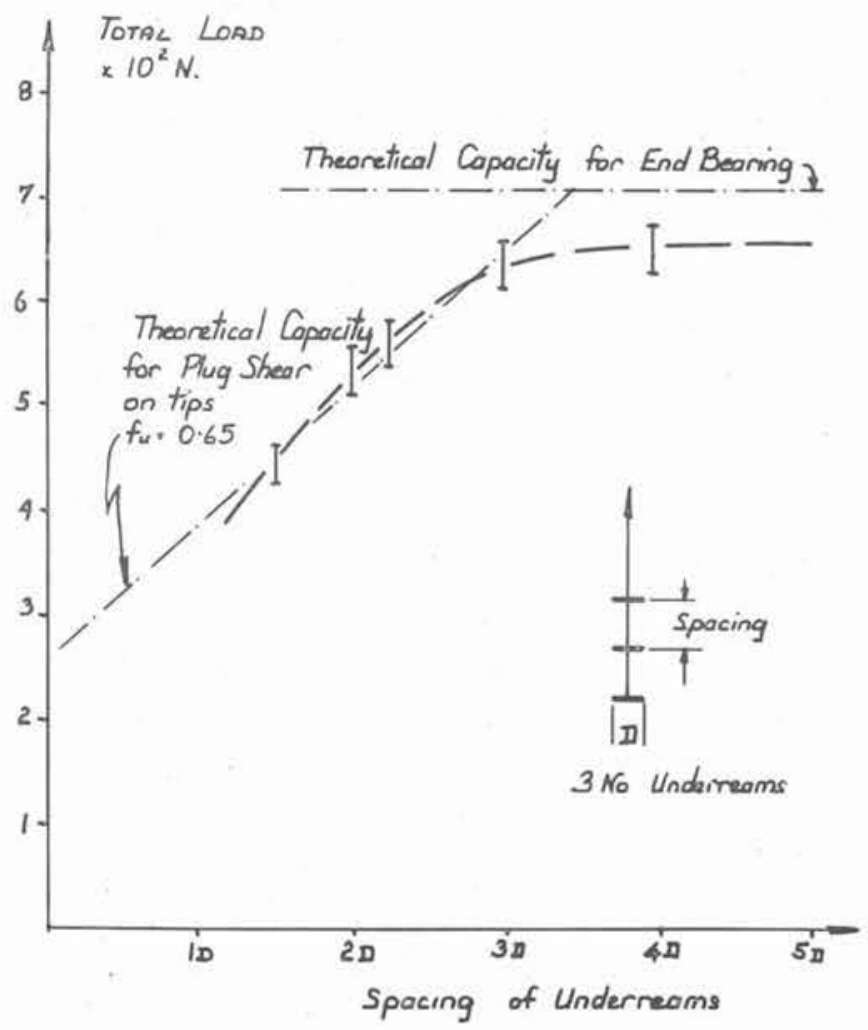

Fig. 6. - Load capacity-underream spacing. 


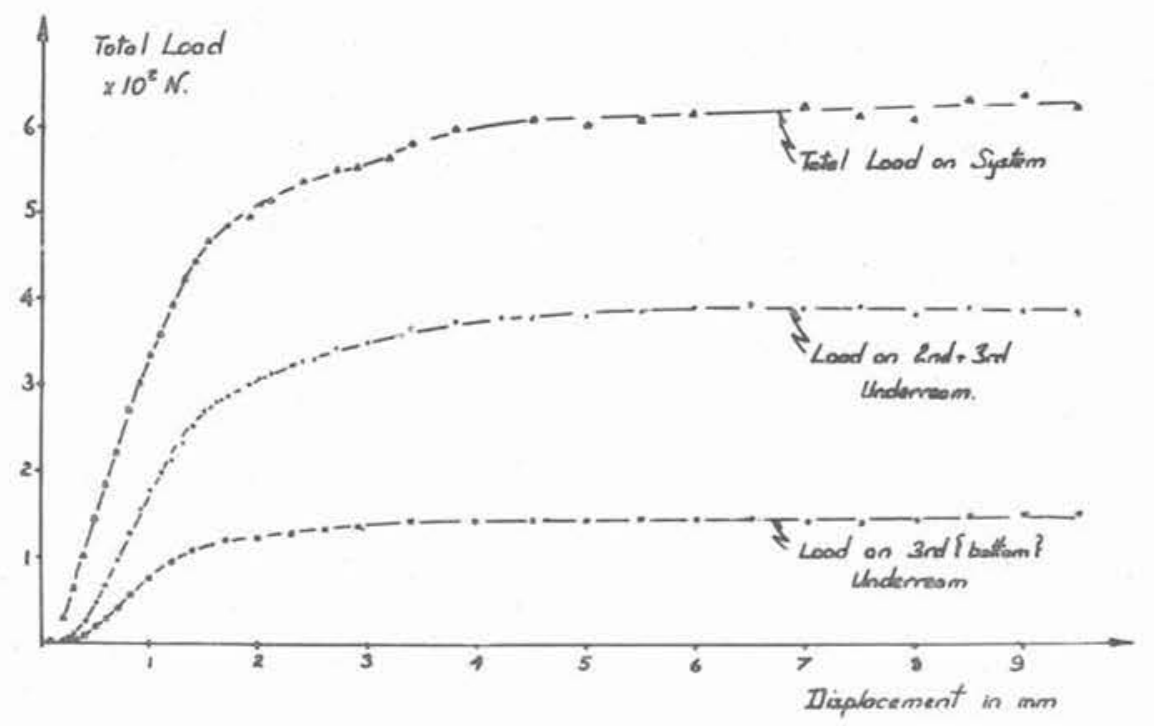

Fig. 7. - Load-displacement characteristics for 3 underreams spaced at 3D.

The theoretical increase in ultimate load up to $\frac{\mathrm{L}}{\mathrm{D}}=3.4$ is also show. The predicted form is closely adhered to but deviation to an end bearing failure is earlier than expected i.e. at approx. 2.9 D. This was

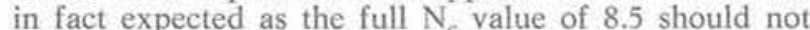
apply to the 2nd and 3rd underreams in end bearing because their capacities will obviously be reduced by the suction zone forming below the disc above. At the experimental $\left(\frac{\mathrm{L}}{\mathrm{D}}\right)_{\text {crit }}$ of 2.9 this suggests that if $\mathrm{N}_{c}=8.5$ applies to the top underream plate a value of only 6.6 is possible on the two lower plates. Separate measurements of the loads on each underream at a spacing of $3 \mathrm{D}$ confirm this figure 7.
$240 \mathrm{~N}$ are carried on the top plate and a total of 380 on the lower two. It should be noted from this graph that the peak capacity of a $L=3 \times D$ set up was not achieved until a displacement of $4 \mathrm{~mm}$ had occured - whereas study of all Potts (1973) data showed that a $1.5 \mathrm{D}$ spacing achieved peak after approximately a $2 \mathrm{~mm}$ displacement.

The maximum effective spacing appeared to be $2.9 \mathrm{D}$ but in view of the earlier comments on loss of capacity, $\mathrm{N}_{c}$ reducing to 5.4 , with time as seepage relieves the vacuum and in order to limit displacements under load, a practical spacing of $2-2.25 \mathrm{D}$ should be adopted. This conclusion is in very close agreement with Mohan, et al (1969) on multi-underream piles.

\section{THE MAGNITUDE OF THE FRICTION}

\section{\& INFLUENCE OF TENDON STIFFNESS}

In view of the data in section 4 the dual mechanism was certainly mobilised at $\frac{\mathrm{L}}{\mathrm{D}}$ ratios of less than 2 . A further series of tests were therefore performed at the $\frac{L}{D}$ ratio of 1.5 with $2,4,6,8$ and 10 underream plates connected with

(i) solid rods, and (ii) stiff coil springs.

The peak results of the solid rod series are shown in figure 8. The dotted line represents the load capacity given by Littlejohhn's equation (1), full $c_{u}$ mobilised on the whole underream plug i.e. $f_{u}$ in equation $(2)=1$.

The experimental data indicates a reduction to an $f_{u}$ of between 0.63 and 0.79 .

This result appears to justify the authors original postulation in (1970) but it does not identify the cause. The waisted shape, i.e. the reduced D, of the failure plugs seen in figure $5 \mathrm{~b}$ and the influence of the underream tips seem possible causes but detailed work by Swain (1976) on the strain patterns round underreams suggests that the rapid migration of excess pore pressure above the underreams to the plug shearing zone causes noticeable softening, even at rapid loading rates.

Figure 8 does however indicate a progressive and virtually linear rise in ultimate capacity with each

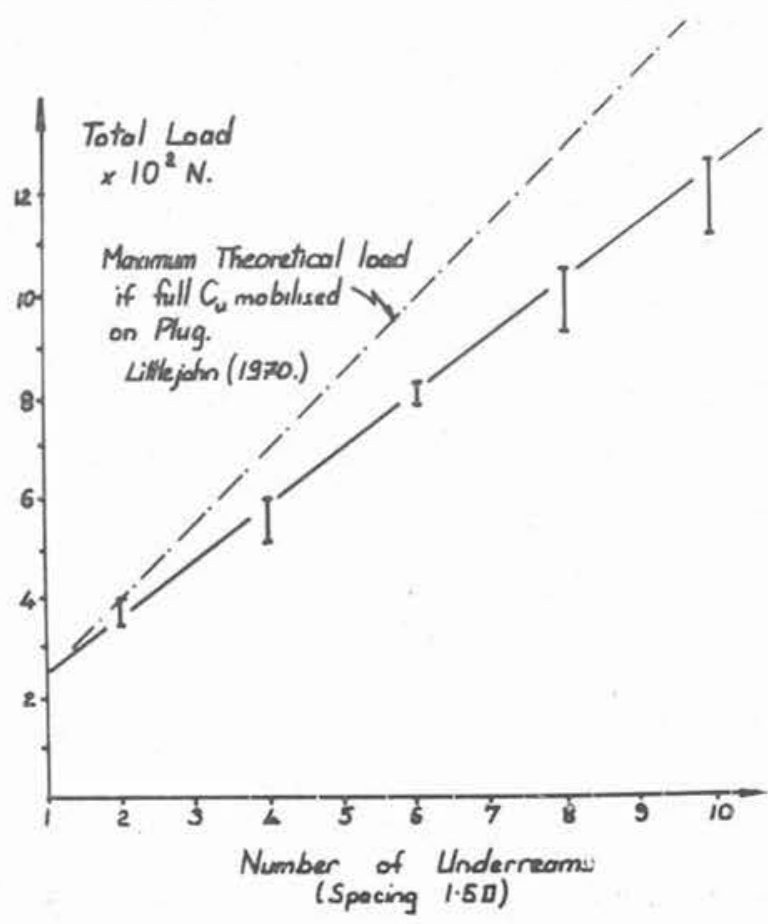

Fig. 8. - Load capacity. Number of underreams. 


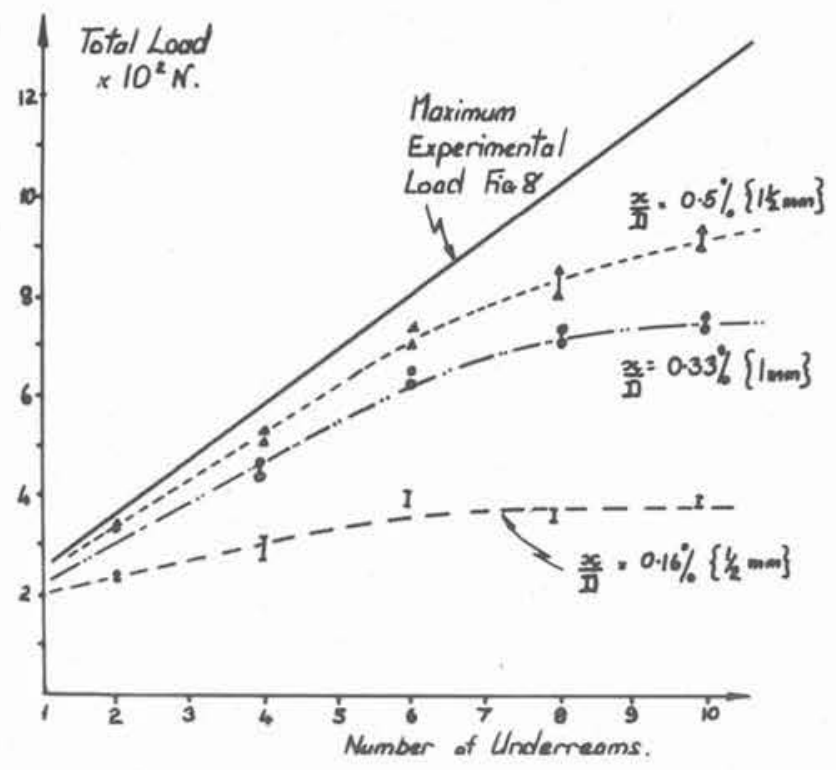

Fig. 9. - Load capacity at various displacements.

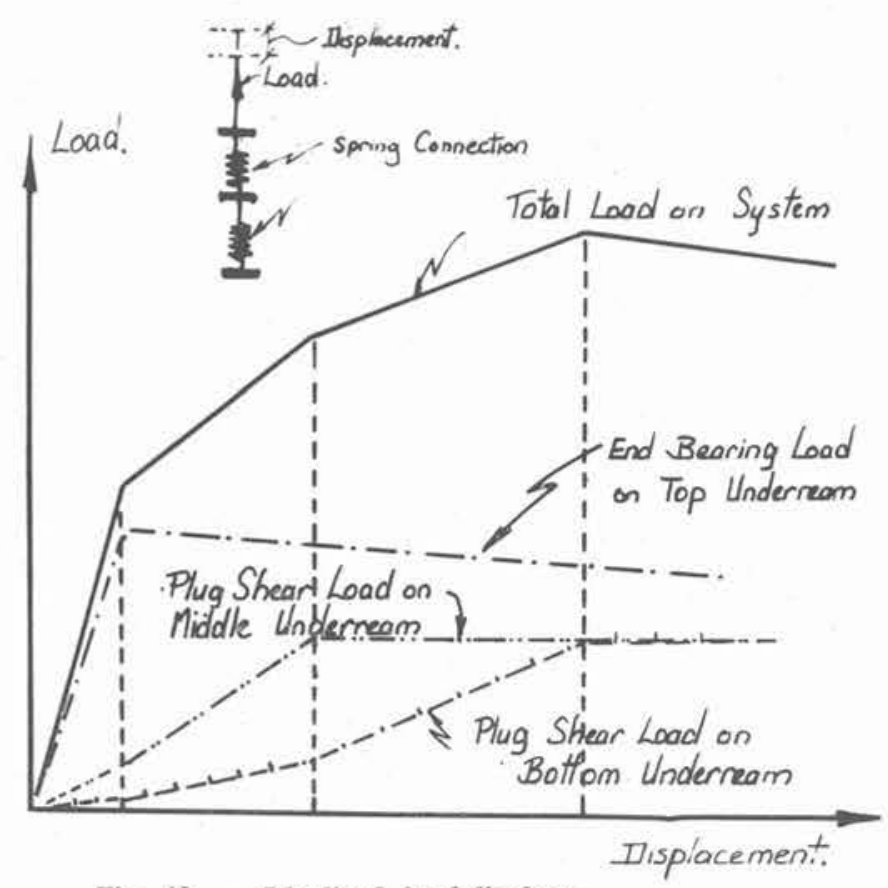

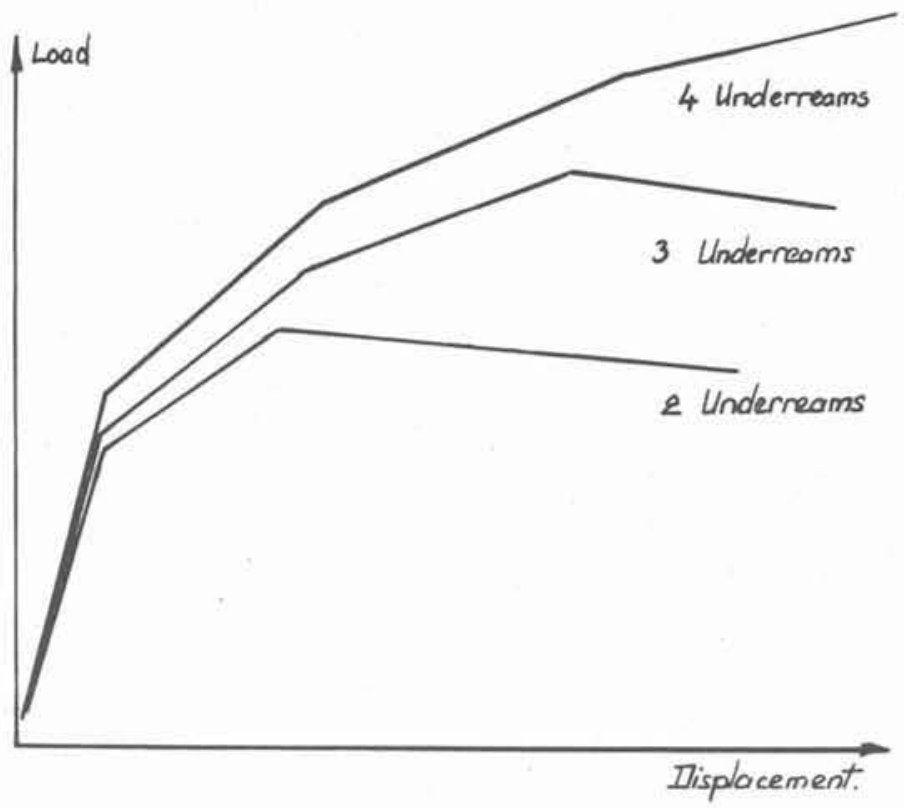

Fig. 11. - Idealised load-displacement for 2, 3 and 4 underream anchors.

additional underream. If howerver additional data showing the load capacity at various displacements is added to figure 9; then at an overall safety factor of 2 it is apparent that very little is gained by the use of more than 6 underreams.

It was suspected that the significance of displacement would be further accentuated in very stiff soils. In the absence of equipment capable of testing marl or shale the soil properties were kept consistent and this feature was examined by reducing the stiffness of the interconnecting tendon member.

The test series described above was repeated, $\frac{L}{D}=1.5$, with stiff coil springs in place of the solid rods $(*)$.

(") The stiffness ratio of $K_{\text {soil }}: K_{\text {tendon }}$ for the rods was 1: 20 where $\mathrm{K}_{\text {soil }}$ is the mean load-displacement slope for the soil at $1 / 2 \mathrm{~mm}$ displacement and $\mathrm{K}_{\text {tendon }}=$ the elastic load-displacement value.
Fig. 10. - Idealised load-displacement for a 3 underream anchor.

Fig. 12. - Experimental load-displacement curves for anchors connected by spring units.

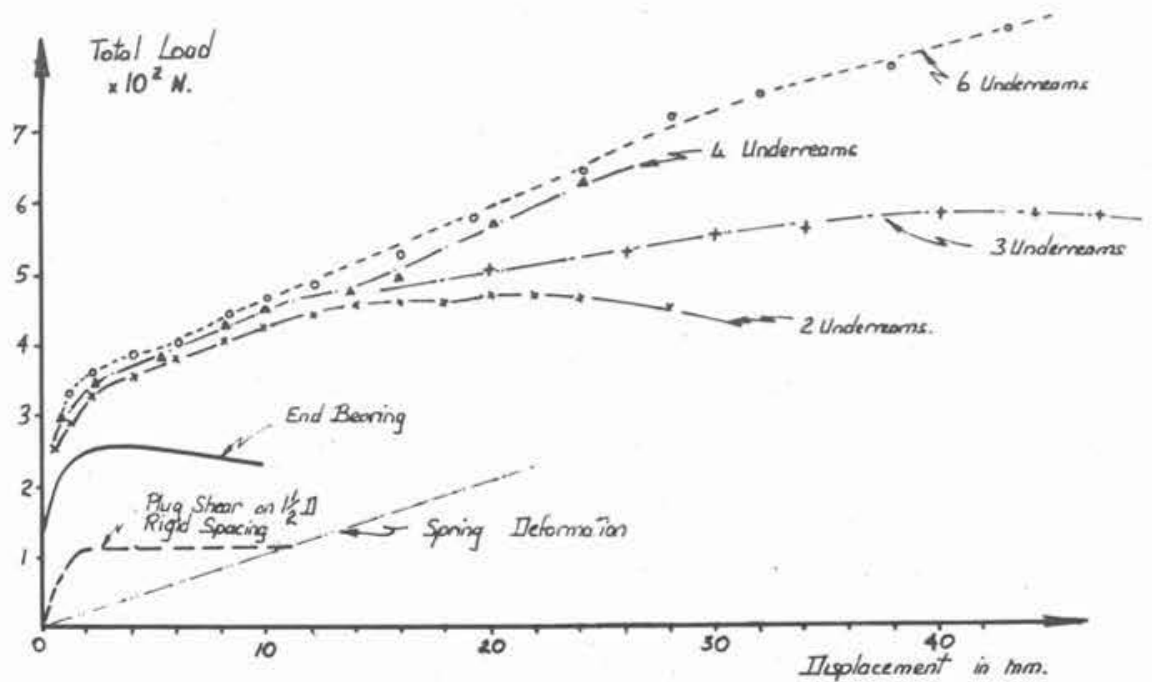

16 
An idealised summation of the behaviour of a 3 underream anchor with weak spring connection is shown in figure 10. (Potts 1973).

The total load curve shows three distinct changes in slope as each successive underream fails. In figure 11 the concept is extended to 2,3 and 4 underream groups.

The corresponding experimental data is given in figure 12. The correct trend is observed, little of significance resulting from the use of more than two underreams. The displacements in this series are some ten times larger than those previously measured. This is due to the unrealistically soft spring tendon members, the stiffness ratio is $\mathrm{K}_{\text {soil }}: \mathrm{K}_{\text {tendon }}=7: 1\left(^{*}\right)$.

In real practice the stiffness ratio of say London Clay to cable anchor tendon is thought to be between $1: 5$ and $1: 3$ and of Keuper Marl to cable anchor tendon nearer $2: 1$ or $1: 1$. So the indications from the soft spring tests may in fact be more representative than those of the solid bar series.

\section{CONCLUSIONS}

The tests have indicated the validity of the composite empirical equation (2) provided that the $\frac{\mathrm{L}}{\mathrm{D}}$ spacing of the underream bells is maintained definitely below 2.9 and if displacements are a limiting factor it is recommended that a value of $\frac{\mathrm{L}}{\mathrm{D}}$ of approximately 2 should be adopted. Its use also implies that the stiffness ratio between the soil and the anchor tendon allows the whole system of underreams to be developing the failure mechanism when the initial end bearing failure condition is reached by the top underream

The end bearing factor $N_{c}$ appears to be approximately 8.5 for rapid short duration loads but it is recommended that a value reduced to 6 should be adopted for permanently loaded situations.

The research described above continues to be developed to broaden its scope. Also several real problems still remain unanswered. A particularly important one is the effects of cyclic loading and very long term creep «settlement" on the carrying capacity and deformations and these are now being investigated

\section{REFERENCES}

BASSETT (R.H.) - Contribution to the Proc. of the Conf. on "Ground Engineering», p. 89-94. ICE London (1970).

BASSETT (R.H.). - Contribution to Session IV of the 5th European Conf. on Soil Mech \& Found. Eng., Vol. 2, p. 330-334, Madrid (1971).

BISHOP (R.F.), HILL (R.) \& MOTT (N.F.). - «The Theory of Indentation and Hardness Tests», Proc. Phys. Soc., Vol. 57, Part 3 (1945).

LITTLEJOHN (G.S.). - (1970) a) "Soil Anchors», Proc. of the Conf. on "Ground Engineering», ICE London. (1970) b) Contribution to the Consulting Engineers. May 1970. (1970) c) Author's reply to the Contributions to the Conf. on «Ground Engineering», ICE London.
LITTLEJOHN (G.S.) (1975), - «List of Ground Anchorage References" supplied privately to the author.

MOHAN (D.), MURTHY (V.N.S.) \& JAIN (G.S.). «Design \& Construction of Multi-Underream Piles», Proc. 7th, Int. Conf. on Soil Mech. \& Found. Eng., Mexico (1969).

OSTERMAYER (H.), - «Construction, Carrying Behaviour and Creep Characteristics of Ground Anchors». Proc. of Conf. on Diaphragm Wall \& Anchorages. LCE, London (1974).

POTTS (D.M.). - «The Performance of MultiUnderreamed Ground Anchor in Clay Soils", Part III Research Project Dept. of Civil Eng., King's College, London (1973).

SWAIN (A.). - "Model Ground Anchors in Clay», Ph.D. Thesis.. Cambridge (1976). 